\title{
Strengthening Institutional Capacity in Realizing an Effectiveness of Strategic Environmental Assessment Implementation
}

\author{
Badrudin Kurniawan ${ }^{1}$ \\ \{badrudinkurniawan@unesa.ac.id ${ }^{1}$ \} \\ Universitas Negeri Surabaya ${ }^{1}$
}

\begin{abstract}
Strategic environmental assessment (SEA) is argued as a tool for formulating and evaluating an informed decision toward sustainability. Indonesia government constitute it within Act Number 32 Year 2009 on Protection and Management of Environment. SEA should be done by either local or national government to incorporate sustainability principle into policies, plans and programs (PPP). However, most face many challenges to accomplish it well. The study aims to analyze implementation of SEA and to recommend alternative solution. The research method is categorized as library research. Author examines this issue within institutional perspective. The weakness of institutional capacity potentially lead to an ineffectiveness of SEA implementation. Author argues that to strengthening institutional capacity require, at least, paying attention on two matters namely documenting best practice of SEA and adopt merged approach.
\end{abstract}

Keywords: Sustainability, Policies, Plans, and Programs (PPPs), Strategic Environmental Assessment, Institutional Capacity, Effectiveness

\section{Introduction}

The first formal implementation of environmental management instruments originated in United States of America together with the enactment of the National Environmental Policy Act (NEPA) in 1969. This policy inspires other countries to do the same. But at the beginning of its development, the focus of this instrument was more on the negative impact of the project. As a result, environmental damage control is considered less effective. This makes countries such as Canada, the Netherlands, Australia and the United Kingdom conduct a higher level of environmental impact studies, namely the level of policies, plans, and/or programs [1]. The study of environmental impacts at the level of policy, recommendations and/or programs is then referred to as Strategic Environmental Assessment (SEA).

Environmental Impact Analysis (EIA) is not always effective in controlling environmental damage. Environmental damage often occurs due to policies or development plans that have been implemented by the government. While EIA is an environmental damage control instrument at the project level. In Indonesia, the existence of SEA began to be increasingly important in the late 1990s. Laksmi Wijayanti, Director of Environmental Impact Prevention of Regional and Sector Policies, Ministry of Environmental and Forestry, said that in that period, the government carried out deregulation where the government simplified the investment process. This is so that many parties are interested in investing in large amounts. Furthermore, EIA is considered to be less effective in preventing environmental damage due to megaprojects that cross regions and across time [2]. 
Post-reform era, environmental damage is increasingly evenly distributed along with the implementation of regional autonomy. This was not only conveyed by Laksmi, but also the previous Minister of Environment (eg. Balthasar in office: 2011-2014) also said that the beginning of regional autonomy was implemented, there was a tremendous increase in environmental damage [3]. Some regions in Indonesia, especially on Java, have many regions whose conditions have exceeded their carrying capacity. Although many areas have not yet reached these conditions, however, each year the carrying capacity decrease continuously. This condition which is also a driver of the implementation of SEA must not only be carried out by central government but also must be carried out by regional government [2]. In Act Number 32 of 2009 concerning Environmental Protection and Management, it is explained that environmental carrying capacity is the ability of the environment to support human life, other living things, and the balance between the two. The carriying capacity is also defined as the ability of the environment to absorb substances, energy, and/or other components that enter or are inserted into it [4].

According to Act Number 32 of 2009, SEA is defined as a series of systematic, comprehensive, and participatory analyzes to ensure that the principle of sustainable development has become the basis and integrated in the development of a region and/or policy, plan, and/or program. Regulations for derivatives, namely Government Regulation No. 46 of 2016 concerning Procedures for Implementing Strategic Environmental Assessment, regulating Central and Regional Governments have to make SEA to ensure that the principle of Sustainable Development has become the basis and integrated in the development of a region and/or Policy,Plan and/or Program (PPP). SEA must be implemented in the preparation or evaluation [5]:

1. Regional spatial plan along with detailed plans, Long-term Development Plan (national and regional level), Medium-term Development Plan (national and regional level) and

2. Policies, Plans, and/or Programs that potentially cause environmental impacts and/or risks

The implementation of the SEA is believed to provide many benefits. In the Handbook of Strategic Environmental Assessment published by the Ministry of Environment, several benefits are mentioned as follows [6]:

1. Identify and consider new opportunities through systematic and careful review of available development options,

2. Consider environmental aspects more systematically at higher levels of decision making,

3. Prevent investment mistakes by reminding decision makers that there are opportunities for unsustainable development from the early stages of the decision making process

4. Better governance is created by the involvement of stakeholders in the decisionmaking process through a process of consultation and participation,

5. Protect the assets of natural resources and the environment to ensure sustainable development,

6. Facilitating cross-border cooperation to prevent conflict, share the use of natural resources, and handle cumulative environmental impacts.

In more than a decade, from 2001 to 2017, 106 SEA have been carried out. Of these hundreds, it include SEA for spatial plan, development plans, master plans, watershed /river /bay, sector/infrastructure, detailed spatial plans, national strategic areas, small island s/coastal 
,urban plans and policy/programs. The application of SEA is also almost evenly distributed throughout Indonesia. The following are data on the distribution of SEA implementation in Indonesia in the period 2001 to 2017.

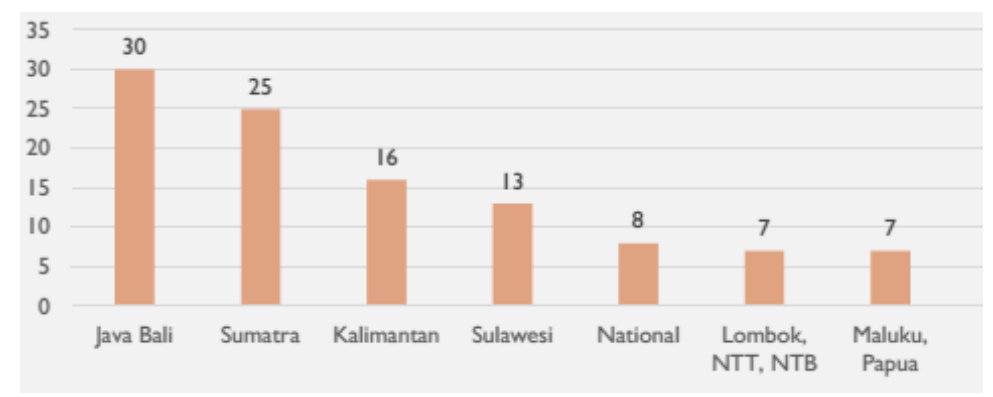

Fig. 1. Strategic Environmental Assessments by Island Group (2001-2017) [7]

Based on Figure 1 it can be observed that the implementation of SEA is still not evenly distributed. The implementation of SEA is still widely carried out on Jawa Island and Bali. This can also be understood because development is also still concentrated in Java. But this is not good because the environmental damage outside Java is also getting worse. Even distribution of SEA implementation needs to be done so that benefits can also be felt equally.

Until now there has been no measure to find out the outcome of the application of SEA. Does the application of SEA have an impact or not, if it has impacts, the impact is large or small, or the impact is positive or negative on the environment. But to be able to know the improvement in environmental conditions per year, it can be seen on the trend of the Environmental Quality Index (EQI) each year. National EQI is a generalization of the environmental quality index of all provinces in Indonesia. The EQI indicator consists of 3 indicators, namely river water quality (RQI), air quality (AQI), and land cover quality (LCQI). Researchers themselves are aware that this index is not fully relevant for assessing SEA outcomes. The following is table 1 National Environmental Quality Index in period 20142017.

Table 1. National Environmental Quality Index 2014-2017 [8]

\begin{tabular}{|c|c|c|c|c|}
\hline Tahun & AQI & RQI & LCQI & EQI \\
\hline 2014 & 80,54 & 52,19 & 59,01 & 63,42 \\
\hline 2015 & 83,84 & 65,86 & 58,30 & 68,23 \\
\hline 2016 & 81,61 & 60,38 & 57,83 & 65,73 \\
\hline 2017 & 87,03 & 58,68 & 56,88 & 66,46 \\
\hline
\end{tabular}

The table above shows that national environmental quality in the 2014-2017 period experienced ups and downs. The fluctuating value was also experienced in the air quality index from 2014, the index amount was 80.54, in 2015 the index rose to 83.84, in 2016 the index fell to 81.61 , in 2017 the index rose again to 87.03 . But this is different from what is experienced by water quality and land cover. Both indexes decline each year. This indicates that there is an increase in forest conversion and water pollution each year. This decline in quality could be due to the expanding and dense industrial growth and settlement. 
Based on these environmental problems, researchers assume that there needs to be an increase in the performance of SEA. This effort can be done by strengthening the capacity of government institutions. This is because government institutions are actor having responsible for producing good quality of SEA. Therefore researchers want to study further about Institutional Strengthening Capacity in Realizing an Effectiveness of Strategic Environmental Assessment Implementation.

The formulation of the problem in this study is how to strengthen the institutional capacityeffectiveness of the strategic environmental assessment implementation. The purpose of this study is to answer the formulation of the problem. The research hopes that the results of this study can provide benefits to readers, government, academics and students in enriching the results of research on strategic environmental assessment in Indonesia.

\section{Literature Review}

\subsection{Institutional Capacity}

The term of institutions and organization could be used interchangeably. According to Uphoff, institutions can be organizations and vice versa although not all institutions are organizations as well. For example, institutions, such as taxation, money, and law, are not organizations. However, other institutions, such as the post office, courts, or local government agencies, are also organizations. In fact, Goldsmith argues the principal meaning of institution in management and organization theory usually refers to a role or organization. Similarly, Brinkerhoff suggests that donor countries, in the context of international development assistance, usually define institutions operationally as organizations [8]. In this study the terms "institution" and "organization" are used interchangeably.

Organizational capacity commonly refers to an organization's ability to perform work or the enabling factors that allow an organization to perform its functions and achieve its goals. Not much different, Imbaruddin, in his thesis, proposes it is defined as the ability of those government agencies to pursue their objectives [8]. Conceptualizations of organizational capacity share a number of common elements. For example, resource availability, robust organizational infrastructure and strong external stakeholder networks. The three elements are identified as important determinants of organizational capacity. Based on the research, Cox et al also reveal effective communication was important to achieve high organizational capacity. It is not discrete component, but it is also in other element namely leadership, strategy, structure/governance and human capital [9].

Cox et al identified three commonly used approaches to understanding what 'high' capacity means for organization. These approaches focus on performance outcomes, compliance with norms and processes, and organizational adaptiveness. First approach emphasize on effective and efficiency process reaching the objective. Second one argues that organization has a high capacity if it fulfill the mandate. The third approach asserts that organization should has a capacity to adjust itself to ever-changing environment and respond to public needs [9].

\subsection{Effectiveness in Strategic Environmental Assessment (SEA)}


Definitions of effectiveness in SEA, and more generally in impact assessment, are not always consistent, and the debate on the different dimensions and nuances of effectiveness is still open (Bond et al., 2013 \& Cashmore et al., 2010). Bina et al. propose to distinguish between procedural, incremental, and substantive effectiveness. Procedural effectiveness focuses on the fulfilment of the procedural and legal requirements of SEA, including for example transparency, independency, and credibility (van Buuren \& Nooteboom, 2009). Incremental effectiveness refers to the contribution of SEA to the broader concept of better environmental governance and management, which include the analysis of SEA outcomes in the medium- and long-term with respect to issues such as social, organizational and institutional learning (e.g., Jha-Thakur et al., 2009). Finally, substantive effectiveness includes the effects that the SEA produce "in the decision-makers' understanding or awareness of environmental and sustainability issues, and in the extent to which such issues are considered throughout the planning and decision-making" (Bina et al., 2011) [10]

\section{Research Method}

This research can be categorized as research libraries because using materials such as books, journals, magazines, video and other library resources as the main data source [11]. This is not the kind of research requires researchers to search for data in the field. In addition, this type of research can be said to be a type of research that is able to facilitate various needs of researchers because it allows researchers to use components from other research methods.

Based on the type of data and its analysis technique, this research using a qualitative approach. Qualitative research results do not obtained through a statistical procedure or another calculation process. This approach directs researchers to elaborate, categorize and link variables examined in a narrative. Although some data can be calculated as well as census data but it is still analized qualitatively [12]. As for the data analysis, this research uses an interactive model. This research does not separate activities of data collection and data analysis [13]. Temporary data analysis results used by researcher as basis for next data collection.

In terms of its purpose, this research can be classified as applied research. The research was oriented on practical application of knowledge and importance of real problems that exist in the community [14].

\section{Result and Discussion}

\subsection{Strategic Environmental Assessment (SEA) Practice and Institutional Challenge}

In the previous elaboration, it was known that the beginning of the emergence of SEA in Indonesia was related to weaknesses in the Environmental Impact Assessment (EIA) instrument. EIA is not relevant for reviewing a program that is cross-time and cross-regional. Then another relevant instrument is needed to review the program, in this case the SEA. However, it is important to note that the existence of SEA is not to replace EIA, but rather to strengthen EIA. SEA is conducted at the level of policies, plans and programs. Whereas EIA is applied at the project level. Therefore SEA will strengthen EIA in order to minimize the negative impact of development on the environment [1]. 
There are some differences between SEA and EIA. SEA involves qualified human resources to formulate macro, systemic and long-term dimensions and strategies (good strategy). While the EIA formulates projects that are environmentally friendly (good design) and are micro, deep and detailed. The focus of SEA is more on sustainability agenda. Therefore SEA moves on the source of impact. While EIA focuses on significant negative impacts and management of environmental impacts. In addition, the SEA's scope is determined by strategic issues. While the scope of EIA is determined by project boundaries, administrative boundaries, and ecological boundaries. Therefore the scope of the SEA analysis can exceed the boundaries of EIA. The strategic issues specified in the SEA have an important role in determining the priority of PPP that will be reviewed. These strategic issues must be representative so stakeholders need to be identified that need to be involved [1].

The implementation of the SEA consists of several stages. This implementation stage has also been regulated in the Minister of Environment and Forestry Regulation Number P.69/MENLHK/SETJEN/KUM.1/12/2017 concerning Implementation of Government Regulation Number 46 of 2016 concerning Procedures for Implementing Strategic Environmental Assessment. There are at least three stages in the making and implementation of the SEA as stipulated in article 13, namely: (1) reviewing the influence of Policies, Plans, and/or Programs on the condition of the Environment; (2) formulation of alternative improvements to Policies, Plans, and/or Programs; and (3) proposing improvement recommendations for decision-making on Policies, Plans, and/or Programs that integrate the principles of Sustainable Development.

In the Handbook of Strategic Environmental Assessment, it is explained that certain PPP need to be screened before entering the stage of reviewing PPP influence. This stage will later identify PPP that cause environmental impacts and/or risks so SEA must be implemented. The screening process includes several steps:

1 Identify the scope of PPP influence based on the scope of ecosystem and its ecoregion

2 Test the PPP's load against the impact criteria and/or environmental risks and sustainable development

3 Make a decision on the results of screening

4 Determine the types of PPP that are based on the results of screening must be carried out by SEA

Next, the review stage of the PPP effect is considered to be more effective if it adjusts the order of formulation and the PPP's charactersistic. The types of PPP that enter this stage directly include Regional Spatial Plan, Medium-term Development Plan and Long-term Development Plan. Reviewing PPP that have general, conceptual and/or macro characteristic can use a strategic approach. Whereas for reviewing PPP that are focused, detailed, bound, limited and / or technical, they are often in accordance with the impact approach. The process of reviewing PPP's influence consists of at least 3 stages, namely (1) identification and formulation of issues; (2) identification of PPP content that has the potential to affect the environment and sustainable development; (3) influence analysis.

The second stage is the formulation of PPP improvement alternatives. The purpose of this stage is to develop various alternative PPP arrangements and ensure sustainable development. Various possibilities of alternative development can be carried out through group discussion methods and/or utilizing the views of experts based on the results of a review of the influence of PPP. The key to the success of this stage is the method of group discussion that is used, the 
involvement of relevant stakeholders, and experts/persons who are in accordance with the content

The third stage is the arrangement of recommendations for PPP's improvement. The purpose of this stage is to agree on improving PPP content based on the results of alternative formulations, and formulating supporting feed back as a consequence of PPP implementation. Content of recommendations can be in the form of: (1) Statement of agreement for improvement of PPP content; (2) Statement of feed back that must be considered and/or implemented by decision makers as a consequence of the implementation of SEA for PPP. Considerations that must be considered in making this recommendation formulation are:

1 Consistency with achieving national sustainable development goals

2 The possibility of scientific uncertainty from the results of SEA

3 Consistency with the application of principles of environmental protection and management

4 Consistency with the application of general principles of good governance

Regulations have set out detailed implementation of SEA. But at the practical level, it still has many weaknesses, especially in the aspect of institutional capacity. This is considered to influence SEA's effectiveness in integrating sustainable development principles in PPP. The expected benefits can be obtained if there is a high institutional capacity. Several presenters attending the National Conference on Strategic Environmental Assessment (SEA) in Jakarta on December 4-5 2017 revealed weaknesses in the implementation of SEA. The presenters were from the government, academics and international donors of the Danish International Development Agency (DANIDA). The following are some of the weaknesses presented by the speaker [2].

1 Policy makers, planners, high-level decision makers do not yet understand SEA utility and the opportunities it provides

2 Lack of or even no budgeting for SEA implementation

3 Limited SEA technical capacity

4 Many trained staff changes, lots of rotation

5 Formulation process of PPP is separate from SEA process. The execution time of both is not match.

6 No measured SEA outcome or impact analysis

\subsection{Strengthening Institutional Capacity: Documenting Best Practice of SEA and Toward Merged Approach on SEA}

Previous explanations show, so far, SEA's practice faces many problems and is also complex. This problem cannot be overcome by government itself. Precisely strengthening the capacity of government agencies requires support from various actors. The actor is mainly from the Center for Environmental Studies. The researcher argues that the subject matter is in awareness of high decision maker regarding the importance of SEA implementation to realize sustainable development goals. The problem causes other emerged problems such as, lack of or even no budgeting for SEA implementation, lots of trained staff rotation, SEA process was separated with PPP formulation one, and none SEA outcome measurement. Therefore, the study center no longer only provided training of trainers for SEA implementers. It should be able to encourage decision maker awareness.

In more than a decade, from 2001 to 2017, 106 SEAs have been practiced in almost all islands in Indonesia. The many processes for drafting SEA are likely to having different experience depending on the type of PPP, regional character, PPP planner character, regional 
leader and others. The difference in conditions is also likely to show different outcomes. The evolving dynamics and different outcomes will provide valuable lessons in initiating steps to improve the implementation of the next SEA in the same area or other regions.

Set of efforts must be held by The Center for Environmental Studies for leading the decision maker being aware on the importance of SEA. The efforts are able to reach substantive effectiveness because decision maker always integrate sustainabilities principle to arrange PPPs. The study center needs to initiate documentation of best practice of SEA. This effort can be done by conducting research on the process and outcome of the implementation of SEA. To measure SEA outomes, the study center needs to make an outcome indicator. This documentation will produce a variety of important findings to improve the curriculum or ToT method they will organize. Hopefully, it can ecourage SEA planner is able to convince the decision maker that the SEA is important to be implemented in order to realize sustainable development. In addition, the results of study center studies can also be disseminated to the government in the form of certain forums.

The following are four models of the SEA implementation approach that are implemented in Indonesia and several Asian countries and the European Union [1]:

1 Environmental Impact Assessment (EIA) -based SEA. In this approach, the SEA implementation resembles an EIA, both in terms of the procedures and methodologies used. Generally SEA is applied to the PPP that has been formulated. Considering that SEA is conceptually directed at efforts to internalize the principle of sustainable development, so the use of this approach needs to be limited

2 Integrated approach. This approach requires the process and procedures for implementing the SEA together with the PPP drafting process, but each process is separate. The results of the approach are in the form of two separate documents, namely one PPP document and the other in the form of environmental reports. These two documents are arranged by different teams.

3 Merged approach. SEA is part of the PPP formulation process. This approach conceptually utilizes sustainable development criteria and indicators as a measure of environmental interests or sustainability rules that must be considered in PPP formulation. This approach only produces one document, the PPP document. However, to show the SEA has been carried out, a brief note is usually provided which contains arguments as to why a PPP is chosen or revised.

4 However, it should be noted that at the level of implementation, often the implementation of SEA does not only refer to one method, but a combination of several ways. This approach can be called a decision-centered approach. In this case the planning and decision-making processes determine the form and direction of the SEA framework. This is to ensure that the SEA implementation process can adapt to the requirements or procedures for decision making in PPP.

In Indonesia, the implementation of SEA uses more EIA-based SEA. Although merged approach and/or decision-centered approach has also been implemented. Using EIA-based SEA approach, PPP planners are usually reluctant to change their designs if there is a recommendation from SEA. It is often caused that planner claim having work hard to create PPP. It will be different when using merge approach. This approach provides communication space for PPP and SEA planner to collaborate starting from formulating strategic sustainable development issues to formulating PPP recommendations. The refusal of input from PPP planners to input from SEA planners is also very possible to minimize.

In practice, this merged approach will not be easy. There is a need for encouraging the implementation. Besides, the decision maker's awareness, detailed process guidance for 
involved agencies is needed to carry out merged approach. The guidance to harmonize the agencies wor such as the National/ Regional Development Planning Agency as a planner and Ministry of Environment and Forestry/ Environmental Agency in the Region as SEA planner. The step towards a merged approach may be difficult but it needs to be started immediately to obtain recommendations for policies that have been integrated with the principles of sustainable development. With the adoption of a merged approach and the documenting of best practice of SEA, the potential to achieve substantial effectiveness can be achieved.

\section{Conclusion}

The technical implementation of the Strategic Environmental Study has been regulated in the Minister of Environment and Forestry Regulation Number P.69/MENLHK/SETJEN/ KUM.1/12/2017 concerning the Implementation of Government Regulation Number 46 of 2016 concerning Procedures for Implementing Strategic Environmental Assessment. The implementation of the SEA consists of three stages (1) reviewing the influence of Policies, Plans, and/or Programs on the condition of the Environment; (2) formulation of alternative improvements to Policies, Plans, and/or Programs; and (3) proposing improvement recommendations for decision-making on Policies, Plans, and/or Programs that integrate the principles of Sustainable Development. For certain types of PPP the screening stage is carried out before the reviewing PPP influence stage is carried out.

Strengthening institutional capacity was carried out to overcome several problems in the implementation of SEA so far. These weaknesses include (1) Policy makers, planners, highlevel decision makers, and not the utility and the opportunities it provides; (2) Lack of or even no budgeting for SEA implementation; (3) Limited SEA technical capacity; (4) Many trained staff changes, lots of rotation; (5) The formulation process of PPP is separate from SEA process. The execution time of both is not match; and (6) No measured SEA outcome or impact analysis. The researcher argued that prioritizing documentation of SEA best practices and supporting the use of a merged approach were able to overcome some of these problems and allow for substantial effectiveness.

\section{References}

[1] C. Asdak, Kajian lingkungan hidup strategis: jalan menuju pembangunan berkelanjutan. Gadjah Mada University Press, 2012.

[2] P. KLHK, "Sesi Pertama Diskusi Sesi Direktur PDLKWS." [Online]. Available: Youtube. [Accessed: 05-Dec-2017].

[3] Anonymous, "Otonomi Daerah Pendorong Utama Kerusakan Lingkungan," 2012. [Online]. Available: https://www.beritasatu.com/nasional/66686/otonomi-daerah-pendorong-utamakerusakan\%0A lingkungan . [Accessed: 29-Jun-2019].

[4] "Act Number 32 of 2009 concerning Environmental Protection and Management."

[5] "Government Regulation No. 46 of 2016 concerning Procedures for Implementing Strategic Environmental Assessment."

[6] B. Sadler, J. Dusik, T. Fischer, M. Partidario, R. Verheem, and R. Aschemann, Handbook of strategic environmental assessment. Routledge, 2012.

[7] C. V. Sluys, "Lesson Learned and Result 10 Years of SEA," It is Present. Natl. Conf. Strateg. Environ. Assess., 2017.

[8] A. Imbaruddin, "Understanding institutional capacity of local government agencies in 
Indonesia," 2003.

[9] K. Cox, S. Jolly, S. Van Der Staaij, and C. Van Stolk, "Understanding the Drivers of Organisational Capacity," 2018.

[10] C. Rega, J. P. Singer, and D. Geneletti, "Investigating the substantive effectiveness of Strategic Environmental Assessment of urban planning: Evidence from Italy and Spain," Environ. Impact Assess. Rev., vol. 73, pp. 60-69, 2018.

[11] Y. Wahyudin, "Humanistic Learning Theory of Carl Ransom Rogers and Its Implications for Teaching Methods of Islamic Education," State Islam. Univ. Sunan Kalidjaga, 2009.

[12] A. Strauss, Basics of Qualitative Research: Procedures and Techniques. Yogyakarta: Pustaka Pelajar, 2009.

[13] B. Bungin, The Philosophical and Methodological Understanding towards Model Application Mastery. Jakarta: Rajawali Press, 2012.

[14] S. Bartolini, "Pure and Applied Research: Striking a Balance," 2011. 